\title{
Preparation and Study of Ferrite Electromagnetic Radiation Gypsum Board
}

\author{
Ying Wang ${ }^{\mathrm{a}}$, Pengqi Wang ${ }^{\mathrm{b}}$, Danjun Tan ${ }^{\mathrm{c}}$, Meng Zhang ${ }^{\mathrm{d}}$, Liang $\mathrm{He}^{\mathrm{e}}$ \\ Research and Development Centre \\ Beijing new building materials public limited company \\ Beijing, 102208, China \\ awy2009@bnbm.com.cn, ${ }^{b}$ wpq@bnbm.com.cn, ${ }^{1}$ tdj@bnbm.com.cn, ${ }^{\mathrm{d}}$ wywhk07@163.com, ${ }^{\mathrm{e} h e l i a n g @ b n b m . c o m . c n}$
}

\begin{abstract}
Electromagnetic radiation pollution has become the fourth pollution sources on a threat to people's health. This paper selects ferrite as an absorbing agent, preparing a new anti-electromagnetic radiation gypsum board. The results show that, absorbing properties of gypsum board decreases first and then increases with the ferrite contents increases. When the ferrite contents was $25 w \mathrm{t} \%$, the absorbing properties of gypsum board was the best, the effective absorbing bandwidth was $5.586 \mathrm{GHz}$ when less than $-5 \mathrm{~dB}$.
\end{abstract}

Keywords: ferrite; electromagnetic wave absorbing; absorbing agent; gypsum board; radiation pollution

\section{INTRODUCTION}

With the rapid of economic development, electronics, communications, computers and electrical equipment are finding their way into the family, resulting in the artificial electromagnetic energy of urban space increased year after year. Meanwhile, broadcasting and TV station, wireless transmitting stations, various types of antennas, electricity grid system, urban transportation, personal wireless communications tools and household appliances and so on, made people in an environment which was full of electromagnetic radiation. So, after air pollution, water pollution and noise pollution, electromagnetic radiation pollution has become the fourth pollution sources as a threat to people's health [1-4].

Ferrite is a magnetic loss absorbing materials with high magnetic loss angle tangent and high permeability, which has the ohmic loss, polarization loss, ion and electron resonance loss as general dialectic material, and also has its unique hysteresis loss, domain wall resonance, natural resonance loss and aftereffect loss mechanisms to absorb electromagnetic waves [5-10].

In this paper, ferrite is main absorbing agent to prepare a new type of anti-electromagnetic radiation gypsum board, and microwave absorbing properties and mechanical properties of these boards were investigated within 2$18 \mathrm{GHz}$ frequency range.

\section{EXPERIMENTAL}

In this study, absorbing performance of the samples with different content of ferrite were tested. Preparation processes of the anti-electromagnetic radiation gypsum board mixed with ferrite is as follows:

(1)Weighing gypsum clinker, ferrite, water, retarder according to the Table 1;
(2)Gypsum clinker mixed with ferrite powders uniformly; retarder mixed in water and stirred uniformly;

(3)Pour the mixed dry powder into the mixture, and stirred; 45 seconds later, the mixed material was poured into $180 \mathrm{~mm} * 180 \mathrm{~mm} * 10 \mathrm{~mm}$ mold for molding, removed the mold after 1 day;

(4)The molding sheet was conveyed to oven, drying at $60{ }^{\circ} \mathrm{C}-70{ }^{\circ} \mathrm{C}$ for about 6 hours until it is $100 \%$ dry to obtain a ferrite gypsum composite.

TABLE I. FORMULA DESIGN OF ABSORBING TESTS WITH DIFFERENT CONTENT OF FERRITE

\begin{tabular}{cccccc}
\hline $\begin{array}{c}\text { Samp } \\
\text { le No. }\end{array}$ & $\begin{array}{c}\text { Gypsum } \\
\text { (g) }\end{array}$ & $\begin{array}{c}\text { Ferrite } \\
(\mathbf{g})\end{array}$ & $\begin{array}{c}\text { Retarder } \\
\mathbf{( \% )}\end{array}$ & $\begin{array}{c}\text { Water } \\
\mathbf{( g )}\end{array}$ & $\begin{array}{c}\text { The } \\
\text { ratio of } \\
\text { water }\end{array}$ \\
\hline F1 & 450 & 50 & $0.2 \%$ & 225 & 0.45 \\
F2 & 425 & 75 & $0.2 \%$ & 212 & 0.424 \\
F3 & 400 & 100 & $0.2 \%$ & 200 & 0.4 \\
F4 & 375 & 125 & $0.2 \%$ & 180 & 0.36 \\
\hline
\end{tabular}

III. RESULTS AND DISCUSSION

\section{A. Determination of Ferrite Electromagnetic Parameters}

The ferrite electromagnetic parameters were measured by Vector Analyzer instrument. Fig. 1 to Fig.4 show the dielectric constant $\varepsilon_{\mathrm{r}}$, dielectric loss tangent $\tan \delta_{\mathrm{e}}$, complex permeability $\mu_{\mathrm{r}}$ and permeability loss tangent $\tan \delta_{\mathrm{m}}$ of ferrite under various frequency within $2-18 \mathrm{GHz}$ frequency range.

Fig.1 and Fig.2 show that the value of $\varepsilon^{\prime}$ was in the range of 5.64 to 5.85 , the value of $\varepsilon^{\prime \prime}$ is almost to zero. The change trend of $\varepsilon^{\prime \prime}$ was similar to $\varepsilon^{\prime}$, which appeared two peaks and three troughs, and their position of the two curves appeared peaks and troughs were quite near. The value of $\tan \delta_{\mathrm{e}}$ almost to zero, and the ferrite used in the experiment did not have the capacity of the dielectric loss.

In Fig. 3 and Fig. 4 , the $\mu^{\prime}$ decreased with the frequency increased overall, which near the range of 0.7-1.6. The values of $\mu$ " were in the range of 0.29 to 0.77 . The trend of $\tan \delta_{\mathrm{m}}$ was increased first and then decreased with the frequency increased, and the values were in the range of 0.19 to 0.69 . which reached the maximum 0.6911 near the frequency $11.8 \mathrm{GHz}$. The results shows that the absorption 
peaks of gypsum mixed with the ferrite might appeared near the frequency $11.8 \mathrm{GHz}$.

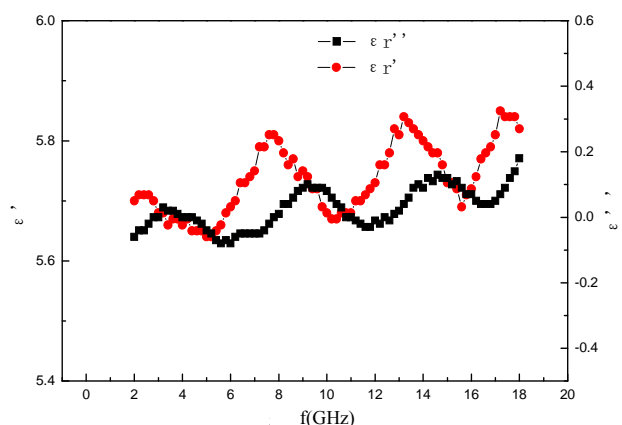

Figure 1. The dielectric constant of the ferrite

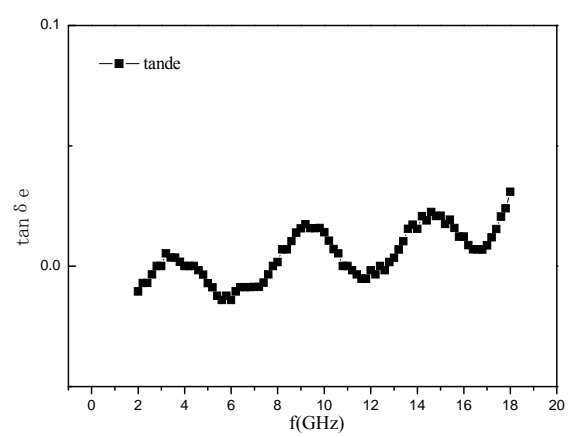

Figure 2. The dielectric loss tangent of the ferrite

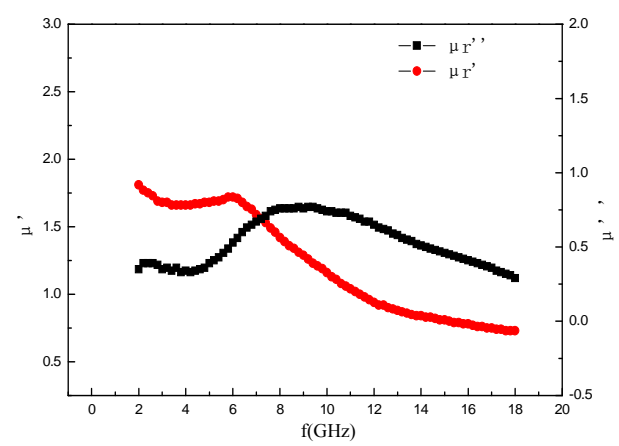

Figure 3. The complex permeability of the ferrite

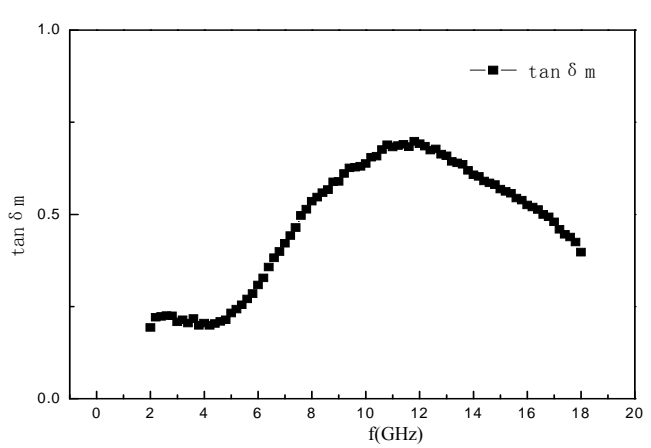

Figure 4. The permeability loss tangent of the ferrite

\section{B. Absorbing Performance Testing of Ferrite Gypsum Composite}

Fig. 5 is the curves between the frequencies and the reflectivities of ferrite with different contents. And Fig.6 described the wave bandwidth of composite system at different contents. From Fig.5 and Fig.6, it could be seen absorbing properties of the system increased first and then decreased with the ferrite contents increased. When the ferrite content is $25 \mathrm{wt} \%$, absorbing properties of the composite system was the best, and the absorbing bandwidth was $5.586 \mathrm{GHz}$, the maximum absorption peaks were $-15 \mathrm{~dB}$ and $-11.5 \mathrm{~dB}$ at $10.32 \mathrm{GHz}$ and $17.12 \mathrm{GHz}$ respectively.

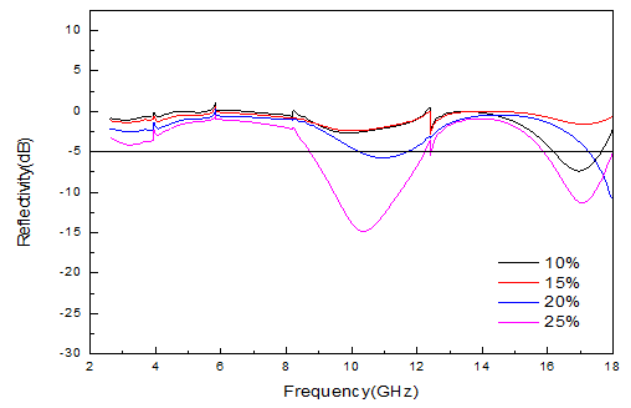

Figure 5. The effect of the ferrite contents on reflectivity

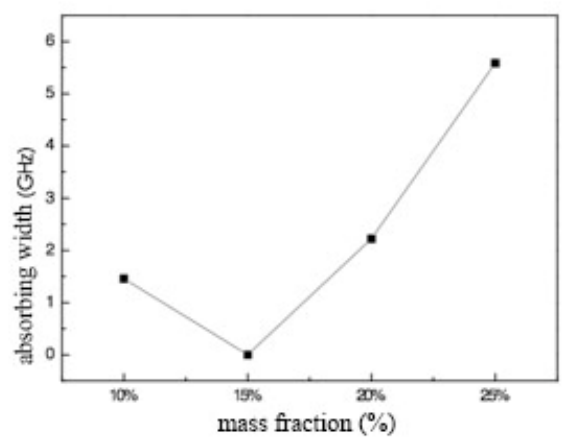

Figure 6. Absorbing bandwidth of composite of gypsum and ferrite

The reasons for these results are as follows: with the ferrite content increased gradually, the permeability of system has increased, and the absorbing property has also improved. But the phenomenon of the impedance mismatch might appeared, which cause the sample of $15 \%$ ferrite contents absorbing properties lower than the sample of $10 \%$ ferrite contents. However, Continued to add ferrite, the hysteresis loss of ferrite enhanced and the absorbing properties of the system has been improved.

\section{CONCLUSION}

Through the absorbing performance testing, absorbing properties of the system decreased first and then increased with the ferrite content gradually increased. When the ferrite contents was $25 \mathrm{wt} \%$, the system has the best absorbing properties. The $-5 \mathrm{~dB}$ bandwidth of the sample is $7.1311 \mathrm{GHz}$, and the maximum absorption peak $-18.467 \mathrm{~dB}$.

\section{ACKNOWLEDGMENT}

This research is sponsored by National Science and Technology Support Project of the 12th "Five-Year Plan" 
(No. 2012BAJ02B04-04). The author would like to thank the support of Zhongguancun Science Park.

\section{REFERENCES}

[1] Vlau G, Ravel F, Vincent F. Preparation and Microwave Characterization of Spherical and Monodisperse Co-Ni Particles[J]. Magnetism and Magnetic Materials. 1995, (2): 140-144.

[2] Jin Fanya, I.TongHonghu, K.Chu Paul, et al. Structure and Microwave-absorbing Properties of Fe-particle Containing Alumina Prepared Bymicro-arc Discharge Oxidation[J].Surface and Coatings Technology. 2006, 201(1-2): 292-295.

[3] Miao Chang wen, Ran Qian ping, Hong Jin xiang. Present Situation and Developmental Trends of Polycarboxylate-Type Superplasticizers [J]. MATERIALS CHINA. 2009, 28(11): 36-43.

[4] Jin Z, Zhang Z Q, Meng L H. Effects of ozone method treating carbon fibers on mechanical properties of carbon / carbon composites[J]. Mater Chem Phys. 2006, 97(1): 167-170.
[5] Chen Ling, Xu Hu-jun, ChenXue. Synthesis and performances of isomeric sodium alcoholether sulphate $[\mathrm{J}]$. Chemical Reagents. 2012, 34(4): 349-352.

[6] Wang Zheng xiang, Li Chung xi, Liu Wen sheng. Research on synthesis and application of polypropylene oxide aliphatic alcohol ether sodium sulfate [J]. Journal of Shan Dong institute of building materials. 1993, 7(4): 56-59.

[7] WiesławHreczuch, KrystynaRolnik, JanSzymanowski. Studies on viscosity build-up properties of sodium alcohol ether sulphates[J]. J. Chem. Technol. Biotechnology. 1999.

[8] Komari H, Konishi Y. Wide band electromagnetic wave absorber with thin magnetic layers. IEEE Transactions on Broadeasting[M]. 1994, 40(4): 219-222.

[9] A.N.Yusoffa, M.H. Abdullah. Microwave Alectromagnetic and Absorption Properties of Some LiZn Ferrites[J]. Journal of Magnetism and Magnetic Materials. 2004, 269(2): 271-280.

[10] Dong-Young Kim, Yeon-Choon Chung. Electromagnetic Wave Absorbring Characteristics of Ni-Zn Ferrite Grid Absorber[J]. IEEE Transactions on Electromagnetic Compatibility. 1997, 39(4): 356-361. 